\title{
O PRÓ-SAÚDE e seus dilemas na universidade privada
}

\author{
Cássia Beatriz Batista \\ Cornelis Johannes van Stralen
}

\begin{abstract}
Resumo: A necessidade de readequação da formação de profissionais de saúde tem exigido aproximações entre universidade, serviços de saúde e demandas da população. Nessa direção, o Programa de Reorientação da Formação dos Profissionais de Saúde (Pró-Saúde) busca incentivar a efetivação das diretrizes curriculares para os cursos de graduação em saúde através de uma articulação entre escola e serviços. Este estudo investigou o desenvolvimento desse programa no contexto universitário. Foram coletados dados sobre a experiência de um programa do Pró-Saúde numa universidade privada (2008-2011) por meio de entrevistas, observação participante e análise de documentos institucionais, enfocando a percepção de docentes sobre a gestão e condições de participação e implantação do projeto. Análise de conteúdo revelou as tensões conhecidas na formação em saúde, porém, foram intensificadas pelo programa ao estreitar relações entre universidade, mercado e identidade profissional. Evidenciou-se que os editais do Pró-Saúde induzem a mudança na formação de profissionais de saúde e que o programa sofre restrições devido às modalidades dos contratos de trabalho dos docentes em universidades privadas. $\mathrm{O}$ estudo aponta também a necessidade de estabelecer monitoramentos e investimentos contínuos, de ampliar a difusão de informações e o compartilhamento dos projetos entre seus municípios e universidades, bem como a adoção de uma metodologia de gestão de mudança para acompanhar os processos, e assim rever estratégias diante dos caminhos da reorientação da formação em saúde.
\end{abstract}

Palavras-chave: Instituições de ensino superior. Integração docente-assistencial. Formação de profissionais de saúde.

\section{The PRÓ-SAÚDE and its dilemma in the private university}

Abstract: The need for readjustment of health professional training has required approaches between universities, health services and demands of the population. In this direction, the Program for Reorientation of Health Professional Training (Pro-Health) seeks to encourage the accomplishment of the health curriculum guidelines in undergraduate courses through an articulation between school and health services. This study investigated the development of this program within a university context. Data on the Pro-Health experience of a private university (2008-2011) were collected through interviews, participant observation, and analysis of institutional documents, focussing on the teacher's perception of the management, the conditions of participation and the implementation process of the project. Content analysis showed the usual tensions within health education, which, however, were intensified as the program strengthened the relationships between university, market and professional identity. It also evidenced how the Pro-Health policies induce changes in health education and how the program was restricted trough the terms of the labor contract of the professors of private universities. The study also highlights the need to monitor the projects and to make continuous investments, to expand the dissemination of information and to share projects between municipalities and universities, as well the adoption of a change management methodology to monitor the development processes of the projects and, in this manner, making possible the revision of strategies of reorientation of health training.

Key words: Higher education institutions. Teaching-care integration. Health professional training.

Este é um artigo publicado em acesso aberto sob uma licença Creative Commons

https://creativecommons.org/licenses/by-nc/4.0/ 


\section{Introdução}

A Constituição Federal de 1988 atribui ao Sistema Único de Saúde a ordenação da formação de recursos humanos na área da saúde e, ao reiterar esta atribuição, a lei 8080, estipula que os serviços públicos integrantes do SUS constituem campo de prática tanto para pesquisa quanto para ensino regulamentadas por normas elaboradas com os estabelecimentos educacionais (BRASIL, 1990). Estes novos dispositivos legais originaram do debate sobre a distância entre a formação dos profissionais de saúde e as práticas de saúde, travado desde os programas de extensão de cobertura dos anos setenta e das Ações Integradas de Saúde na década de 80 e que desembocou na proposta de Integração Docente-Assistencial.

A implementação do SUS e o esforço de construir uma rede de atenção primária tornou a criação de um novo perfil de profissionais de saúde uma questão estratégica e gerou novas forças e iniciativas de aproximar as instituições formadoras e os serviços por meio da reorganização dos cursos de graduação como apontam as Conferências Nacionais de Saúde e de Recursos Humanos. Principalmente entre 2001 e 2005, foi emitida uma série de dispositivos legais e normativos visando à readequação da formação dos profissionais tais como as Diretrizes Curriculares Nacionais dos Cursos da Área de Saúde, o Programa de Incentivo às Mudanças Curriculares nos Cursos de Medicina - PROMED, a Política Nacional de Educação Permanente em Saúde e o Programa Nacional de Reorientação da Formação Profissional em Saúde - Pró-Saúde (BATISTA, 2013).

O Pró-Saúde contemplava inicialmente apenas os cursos de Medicina, Enfermagem e Odontologia, mas em 2007 foi estendido para todos os demais $\operatorname{cursos}^{1}$ de graduação da área de saúde com o objetivo expresso de reorientar a formação de profissionais de saúde com enfoque na atenção primária à saúde (BRASI, 2007). Seus editais disponibilizam recursos financeiros para desenvolvimento de projetos elaborados e submetidos por instituições de ensino superior em conjunto com Secretarias Estaduais e/ou Municipais de Saúde. Assim o Ministério da Saúde toma o papel de indução de mudanças na formação dos profisssionais de saúde.

A complexidade do processo de mudança visada - perfil de formação profissional, conhecimentos gerados e serviços prestados de acordo com as demandas e necessidades da população usuária - exige uma compreensão clara da resistência a mudanças produzida por práticas instituídas, seja na universidade, seja nos serviços de saúde e das possibilidades de um

\footnotetext{
${ }^{1}$ Os demais cursos de saúde que totalizam 14 são: Biomedicina, Ciências Biológicas, Educação Física, Farmácia, Fisioterapia, Fonoaudiologia, Medicina Veterinária, Nutrição, Terapia Ocupacional, Psicologia, Serviço Social.
} 
concatenamento de mudanças em instituições que possuem distintas lógicas institucionais e são tencionadas pelos conflitos do mercado de trabalho.

A universidade encontra-se duplamente provocada diante das crescentes demandas e cada vez mais, diante da diminuição do financiamento público para suas atividades, exigindo mudanças estruturais (SANTOS, 2010). Contudo, a reprodução da instituição universitária, ajustada à funcionalidade e à organização rígida, torna-a resistente a mudanças. Ainda assim, a partir da década de 1970, os objetivos da universidade passaram por transformações, acumulando diferentes funções, inclusive, contraditórias. O ensino, a investigação e a prestação de serviços caracterizam essa nova universidade, privilegiando a dimensão produtivista e utilitária do conhecimento em detrimento de sua dimensão cultural. Temos, então, pontos de tensão no interior da universidade, gerados pelas colisões entre a função do ensino e da pesquisa; entre a formação generalista e cultural e a formação profissional especializada e técnica (SANTOS, 2010).

Todas essas tensões, de acordo com Santos (2010), respondem a outras incongruências do sistema capitalista desorganizado em que vivemos atualmente, agravando a crise da hegemonia e de legitimidade institucional da universidade. Além da perda da centralidade na produção de cultura-sujeito, há uma perda de hegemonia associada à organização dicotômica e sequencial da educação e do trabalho. Contudo, os processos produtivos modificam-se de forma acelerada, rompendo com a sequência temporal educação-trabalho, colocando-os como concomitantes e fundindo-os em um único processo produtivo, que exige formação permanente.

O campo profissional sofre pressões do mercado de trabalho e passa por disputas corporativos em torno da delimitação de campos de trabalho legitimados por posse de diplomas e por currículos universitários. Como Abbott aponta, cada profissão tem uma jurisdição, ou seja um vínculo entre profissão e trabalho legitimado ou justificado por conhecimentos, fazendo com que a universidade se torne um importante espaço de dominação e competição entre profissionais. A jurisdição reforça a divisão técnica do trabalho e, de certa forma, os locais de trabalho aceitam e aderem à divisão de saberes existentes (BARBOSA; SANTOS, 2011). Sendo assim, readequar perfis profissionais vai além de mudanças curriculares. Nesta perspectiva, o Pró-Saúde está centrado na integração e na articulação entre a universidade e os serviços, possuindo três eixos desenvolvimento: orientação teórica, cenário de práticas e orientação pedagógica.

Pautado por estes eixos, este estudo busca compreender vivências e mudanças, trazendo contribuições para o campo da formação em saúde na graduação, ao sistematizar desafios e 
pontos de tensão relativos ao processo de reorientação da formação promovido pelo Pró-Saúde, no contexto da universidade.

\section{Procedimentos de Pesquisa}

O estudo analisa a experiência do Pró-Saúde a partir de sua execução em uma universidade privada da cidade de Belo Horizonte, entre os anos 2008-2011, em parceria com a Secretaria Municipal de Saúde. Esta universidade estudada teve projetos aprovados em três editais do Pró-Saúde, lançados nos anos de 2005, 2007 e 2012. O primeiro edital contemplou dois projetos de cursos diferentes, Odontologia e Enfermagem, em parceria com as prefeituras de municípios distintos. Já no segundo edital - Pró-Saúde II, a universidade aprova um projeto único com a prefeitura de Belo Horizonte e cinco cursos de saúde: Fisioterapia, Enfermagem, Fonoaudiologia e os dois cursos de Psicologia. Com duração prevista de três anos, o projeto foi implantado em 2008, agregando o curso de Odontologia aprovado no Pró-Saúde I. O último edital de 2012, não fez parte dessa análise, mas revela a continuidade da proposta de mudança na formação superior de profissionais de saúde articulado com o Programa de Educação pelo Trabalho na saúde - PET-Saúde.

Diante de um objeto de pesquisa social, histórico e inacabado (MINAYO, 2000), que veicula visões e interesses advindos de um contexto e de uma posição política e social definida e que, além disso, refere-se à relação entre sujeito-pesquisador e sujeito-pesquisado, esse trabalho torna-se interventivo ao provocar reflexões ou deflagrar processos de autoanálise e produção de novos discursos sobre o tema (BATISTA, 2015).

Assim, nessa abordagem qualitativa, priorizou-se neste artigo a perspectiva da universidade, a partir da percepção de seus professores e da pesquisadora, também professora nessa instituição no período de pesquisa. Para tal, utilizou-se da análise temática de conteúdo (MINAYO, 2000) tendo como fonte documentos institucionais, anotações/impressões da pesquisadora e entrevistas de quatro professoras que compunham o colegiado ampliado do PróSaúde na instituição, representantes de diferentes cursos, a saber: enfermagem, fisioterapia, fonoaudiologia e psicologia. A pesquisa seguiu a Resolução CNS 196/96 e teve aprovação do Comitê de Ética em Pesquisa com CAAE - 00260213 000-10. 


\section{Resultados e discussão}

Os resultados apresentados são um recorte de um estudo mais amplo que aqui foi organizada em torno (1) da implantação do programa universidade, (2) da gestão do programa, (3) do trabalho docente na execução.

\section{A Implantação do Programa na universidade}

O Pró-Saúde II inicialmente foi impulsionado pela Coordenação Integrada de Estágios da universidade, que convocou os cursos de saúde a participarem da construção do projeto comum em 2007. Primeiramente, o envolvimento ocorreu por parte de coordenações de cursos e professores de estágios que desenvolviam atividades curriculares nos serviços públicos de saúde. Com interesses e características específicas em inserir ou ampliar seus campos de estágios na rede pública, os cursos de saúde foram se reunindo em torno da proposta do programa interministerial.

Grande parte dos professores participantes da coordenação do projeto na universidade são coordenadores ou membros do colegiado dos cursos de saúde, com horas de dedicação para diversas ações, e, no momento de adesão ao Pró-Saúde, alguns destes estavam revendo seus projetos pedagógicos de curso para readequá-los às Diretrizes Curriculares Nacionais e promover, assim, uma convergência de esforços e interesses.

Com o decorrer do projeto, outros professores com estágios em saúde ou disciplinas no campo da saúde coletiva foram sendo convidados ou indicados pelos cursos para participarem do projeto, constituindo-se, desse modo, um grupo de professores envolvidos com o desenvolvimento do Pró-Saúde.

\footnotetext{
Eu entendo que foi uma construção. Quando começou na realidade, todo mundo tava motivado na construção do projeto, mas a gente não tinha a menor ideia de como é que seria esse projeto, de como é que ele se daria na prática e que benefícios ele traria para além da questão financeira. Porque eu acho que, no princípio, quanto teve edital com... com o valor dos projetos que iam ser financiados, eu acho que teve muito mais uma preocupação nessa questão de um repasse financeiro, né? Porque o resto era muito incipiente, a gente não tinha noção de como é que seria. Mas desde o princípio foi uma construção coletiva. A gente construiu o projeto com vários cursos envolvidos e depois a própria implementação, ela foi também sendo construída de forma coletiva. [...] E eu acho que foi um momento que foi feliz, porque foi um momento em que vários cursos estavam pensando o projeto político-pedagógico do curso. Então, acabou que teve uma convergência aí de ações pra que ele se efetivasse na prática e fosse tomando corpo e a gente entendendo o que que era esse Pró-Saúde. [....] Quando o Pró-Saúde surgiu a gente estava já construindo o projeto político pedagógico do curso. Já tava na fase de aprovação do projeto e o que foi feito na verdade foi assim... foi somar esforços, né? O que tava proposto no novo projeto encontrou um cenário propício a partir de ações que passaram a ser não só do curso de Enfermagem, mas ações institucionais, né? (Jasmim, professora do curso de enfermagem).
} 
Depois de aproximadamente um ano de trabalho, o grupo de professores a frente do projeto na universidade se dividiu em três equipes de trabalho: (1) inserção no cenário de práticas, (2) educação permanente em saúde e (3) pesquisa, avaliação e extensão. Dentre essas equipes, a inserção nos cenários de prática se revelou a ação mais presente, não só por causa do vínculo do programa na universidade ser através da Coordenação de Estágios da universidade, mas também por ser o eixo que permite a aproximação de estudantes e professores com a realidade dos serviços de saúde e a participação na resolução de problemas de atuação colocados pelo programa. O eixo Cenários de prática apresenta como vetores a integração ensino-serviço, a diversificação de cenários de aprendizagem e a articulação dos serviços universitários com o SUS, abordando, assim, os estágios curriculares e a clínica-escola na intenção de articular processos educativos às práticas e demandas dos serviços de saúde. Nessa direção, o projeto da universidade contempla em seus objetivos e ações o cenário de práticas ao propor antecipar a inserção do aluno na Atenção Básica de Saúde, ampliar e aprimorar a participação de alunos no programa de estágio curricular supervisionado em unidades do SUS bem como integrar a clínica- escola com os serviços.

A equipe de inserção no cenário de práticas tem o maior número de professores participantes, sendo estes supervisores e coordenadores de estágios, ou seja professores com trabalho docente diretamente correlacionado com a atividade da equipe. A necessidade inicial do projeto em ampliar e efetivar a inserção de alunos nos cenários de práticas, também justifica o agrupamento maior de professores nesse grupo, fortalecido ainda pelo momento de implantação dos Núcleos de Apoio à Saúde da Família (NASF), que garantem novas inserções profissionais nos serviços de atenção primária à saúde, com a entrada de fisioterapeutas, psicólogos e fonoaudiólogos para a rede pública de saúde de Belo Horizonte.

\footnotetext{
Eu percebo que tem um interesse [dos professores] crescente, né? Mas ainda tem um desconhecimento muito grande e eu acho que por causa do desconhecimento tem a falta de envolvimento [com a proposta do Pró-Saúde] e um medo também de ser uma coisa muito difícil, muito abstrata. Você tem que saber mesmo o que é atenção primária, você tem que entender de lei, o que é o sistema de saúde, para você entender o que é o Pró-Saúde, e também o que eu percebo é que o curso de Fisioterapia, como foi um curso que ele sempre foi muito elitizado, Fisioterapia agora que tá começando a ficar mais acessível para as pessoas como um outro jeito do fisioterapeuta ficar mais próximo da população, principalmente com a criação dos NASF, né? E que tem mudado mas ainda uma dificuldade muito grande ficou do professor compreender bem o que é o Pró-Saúde, para fazer com que o aluno, o aluno, engajar o aluno no processo. Por que não adianta nada eu só dar uma disciplina teórica se eu não conseguir trazer para a prática esses conceitos que foram passados e que muitas vezes esses professores não sabem nem esses conceitos. [...] Então, eu acho que ainda tem um envolvimento pequeno. E eu percebi também que, assim, que quando tem os seminários, os encontros de planejamento na [universidade], que muitos professores participam, muitos participam para cumprir a carga horária, e que tem informação muito grande [...] que leva ao baixo envolvimento (Rosa, professora do curso de fisioterapia).
} 
De forma geral, a participação docente fica concentrada em alguns professores de estágios, coordenadores de curso e outras representações institucionais, como na área da extensão, além de alguns professores das áreas de Saúde Coletiva e da Psicologia Social. A participação docente é, então, configurada pelos vínculos de trabalho e depende em grande parte do regime de dedicação estabelecido com a universidade, ou seja, de lugares e dos contratos de trabalho (por aula- 'aulista' ou por hora) ou de alguns professores que investem voluntariamente devido à sua ligação direta com a discussão do SUS, como profissional ou supervisor de estágio na rede, ou ainda outros interesses profissionais e institucionais.

[...] assim que a [universidade] quis fazer né? o projeto, a coordenação de Fonoaudiologia perguntou se eu queria atuar. Como eu já dava aula de saúde coletiva... então desde as primeiras reuniões que foi né? fazer o projeto, eu lembro de finais de semana em casa, a gente trabalhando muito sobre isso. Então, a entrada se deu dessa maneira. [...] Então, eu era uma das professoras que estava disposta a ir pro centro de saúde e quando foi feita essa divisão né?, que o Pró-Saúde resolveu né?, toda a equipe resolveu: vamos trabalhar em grupos, porque se não ia ficar uma coisa muito grande, né? [...] olha então, é... voluntária, eu quero entrar nesse, né? Eu não acho que eu tive... pra mim, qualquer um seria interessante. Mas eu acho que foi muito por conta de eu já tá lá naquele cenário, né? (Margarida, professora do curso de fonoaudiologia).

[...] iniciou com o coordenador de estágio, que teve essas atividades todas, essas reuniões, então, precisa ter essa dedicação toda, tem que ser uma pessoa aulista, né? isso que eu te falei tem que ser além daquilo como professor, né?! Porque são muitas reuniões, tanto na [universidade] como na Prefeitura, precisa de horas de dedicação. Então, aí já começou ser um critério, ter [horas de dedicação e aí dentro disso também né? juntou a disponibilidade e o interesse, e aí foi casando, e a escolha foi sendo feita em função dessas situações aí, né? Do professor ter horas, não ser só aulista, aí foi favorecendo mais essa dinâmica de funcionamento (Girassol, professora do curso de psicologia).

Nota-se que muitos docentes conhecem pouco o programa ou não podem participar das reuniões e atividade deste. Essa situação separa ‘aqueles que são’ do Pró-Saúde com vínculos claramente estabelecidos dos que não aderiram ou desconhecem a proposta.

[...] há uma linha tênue aí separando esse... o professor que tá nesse cenário [...]. e aquele professor que não está. Então, é uma pescaria que a gente faz ali né? diariamente né? tentando... vê na sua disciplina, aí, que que você pode colocar isso? Dá um tempo aí pro seu aluno absorver tais coisas, que isso ele vai usar daqui a pouco!... é... libera o seu aluno pra ele poder participar de uma reunião!... que muitas vezes não era o horário do estágio com o professor do Pró-Saúde. [...] E eu ainda acho que tem pouco envolvimento, sim, dos professores, apesar da coordenação apoiar muito, é um envolvimento pessoal mesmo, que eu não percebo né?, muitas vezes, nos meus colegas, por conta disso... Ah, eu não vou em centro de saúde... fica uma coisa quase Pró-Saúde, é só centro de saúde né?, infelizmente. [...] Porém, entendo esses meus colegas, porque tá todo mundo com atribuições demais também, então, já tem tantas atribuições e ainda vou ter que -mudar alguma coisa ou remanejar por conta disso. Então né?, tem que ser uma coisa maior, um envolvimento maior, pra que ele entenda que o Pró-Saúde é um braço né?, só, mas que as coisas estão funcionando como um todo. Então, tem que ter esse envolvimento, sim, mas ainda tá muito focado, é como eu tenho que mudar porque eu sou Pró-Saúde. Não é por conta disso. São mudanças, tem que ser interna primeiro, né? E aí dar conta de entender porque que superficialmente ele também tem que mudar algumas coisas na disciplina dele ou na maneira dele de, de dar o estágio, tá? (Margarida, professora do curso de fonoaudiologia). 
As reuniões de equipe apresentam um caráter maior de gestão, com poucos momentos coletivos de reflexão institucionalizados que favoreçam diálogos e trocas sobre concepções, posturas, crenças e que possibilitem ressignificações e novas questões necessárias para aprimorar a atuação docente. Como apontado por Stanga e Rezer (2015), as potencialidades da ação comunicativa precisam ser repensadas em novas articulações e garantias de contextos de interações.

Sobre a implantação do Pró-Saúde, Morais e outros (2010) identifica em seu estudo que o conhecimento sobre o projeto é parcial e fragmentado, necessitando de uma maior sensibilização, tanto na rede quanto na universidade, e da compreensão do projeto pactuado entre os ministérios, municípios e universidade, bem como do estabelecimento de relações dialógicas na constituição das parcerias interinstitucionais.

Em 2011 dentro da universidade, o programa deixa de ser vinculado ao setor de estágios e se agrega à diretoria do Instituto de Ciências Biológicas e da Saúde (ICBS), em parceria com a Faculdade de Psicologia. Passados mais de três anos de discussão e implantação do Pró-Saúde, a participação dos professores foi crescendo gradativamente com as ações de (in)formação e de inserção dos alunos nos estágios e mais uma vez com destaque do eixo Cenários de prática. Contudo, grande parte dos professores ainda leciona disciplinas (teóricas ou práticas) no campo da saúde pública e saúde coletiva e continuam dando ênfase no ensino com pouca abertura tanto para a participação de professores de outras áreas quanto para o desenvolvimento de projetos de extensão, de pesquisas e pós-graduação. E mais: a maioria dos professores leciona apenas em seu curso de formação restringindo os debates e as posturas interdisciplinar e multiprofissional, que na perspectiva do Pró-Saúde são alicerces da reorientação da formação e da prática em saúde.

Sabemos que essa postura interdisciplinar não depende simplesmente de uma reestruturação curricular, já que é atravessada pela relação entre o mercado de trabalho, categorias profissionais, saberes científicos, concepções de multidisciplinaridade, multiprofissionalidade, condições de trabalho, políticas educacionais, pressões externas, como as do MEC e pressões internas de sobrevivência dos cursos diante da ampliação de cursos privados na cidade ou diminuição da procura de cursos de saúde, ameaçando os postos de trabalho dos professores.

[...] mas não foi só por causa do Pró-Saúde [que houve mudanças], adequação à nova realidade das escolas. O MEC exige uma coisa, um número de horas, a escola tem que pensar na manutenção do curso, o número de alunos já diminui com o aumento das escolas particulares em Belo Horizonte, no Brasil, né? Mas em Belo Horizonte também, então, turnos que fecham né?, diminuem turmas. Então, o currículo é mudado também em função de outras coisas, mas também em função do Pró-Saúde. O colegiado [do 
curso] fica muito preocupado com isso. O colegiado está bem próximo dessa discussão né?, de necessidade de mudanças de matrizes de disciplinas para poder aprender, porque é interessante para escola que os alunos saiam e tenham um futuro profissional, e o mercado de saúde hoje, dos profissionais de saúde, hoje, tá muito restrito, não tá? E a gente sabe que o empregador público, ele é o principal empregador de saúde, onde tem mais vagas hoje no mundo e principalmente no Brasil, porque $70 \%$ da população é usuária do sistema público de saúde, então, o governo tem que dar conta disso, tá lá na Constituição, não tem? Que, apesar de toda precariedade do sistema público de saúde, está na constituição e cada vez mais a população tá cobrando isso. Então, para o fisioterapeuta, para o psicólogo, para o fonoaudiólogo que formem incluídos na atenção primária, isso é importantíssimo a escola tem que saber, né? Ela quer que o aluno saia e tenha futuro, tenha emprego, né? Vai formar para quê? (Rosa, professora do curso de fisioterapia)

As modificações vividas no trabalho no setor da saúde e as exigências de projetos pedagógicos das graduações conforme as novas diretrizes curriculares propiciaram um campo fértil para o desenvolvimento do Pró-Saúde que de fato impulsiona discussões intercursos e alterações curriculares, confirmando que o incentivo governamental por meio do Pró-Saúde acelera ou amplia, em certa medida, a reorientação da formação apontada pelas diretrizes curriculares nacionais. Entretanto, a forma e as condições de trabalho que os programas e as mudanças veem ocorrendo nas universidades devem ser observadas.

\section{A gestão do Programa}

Tanto as universidades públicas quanto as privadas estão inseridas no contexto do capitalismo e sofrem pressões do campo profissional e econômico, ainda que o grau da autonomia de cada uma seja diferente. Mesmo que as concepções ideológicas do regime capitalista estejam presentes em toda a sociedade, a relação entre mercado e necessidade social de saúde é bem tensionada nas instituições universitárias, e essa interfere não apenas na gestão, mas também na elaboração dos projetos e nos processos de submissão destes. Essa tensão aparece em diferentes editais de incentivos governamentais, em seus convênios, parcerias e cooperação técnica, seja na concessão de bolsas de estudos e de auxílio às pesquisas, na realização de especializações por demandas governamentais e mesmo na produção de materiais educacionais.

A lógica atual de editais acaba restringindo a participação em programas de cunho universal, como o caso da reorientação da formação dos profissionais de saúde ${ }^{2}$. Isso fica

\footnotetext{
${ }^{2}$ Em 2008, a universidade estudada já contemplada pelo Pró-Saúde II, se organizava para participar do edital do PET-Saúde da Família, quando foi surpreendida com a exigência de RTI para ser tutor, além de ter o curso de Medicina para participar da seleção, critérios estes que excluiriam a universidade e outras tantas confessionais, comunitárias ou privadas que são responsáveis pelo maior número de alunos em formação no país. Outro fato recorrente a ser revistos nos editais são os prazos e períodos dos editais que desconsideram o calendário escolar das instituições de ensino superior.
} 
explícito em editais que colocam como critério o Regime de Tempo Integral (RTI) para professores serem tutores dos projetos, ou mesmo outros programas que priorizam parcerias exclusivas com instituições públicas. Bonfim e Silva (2003) sinalizam um clima de desconfiança entre as esferas pública e privada e que, mesmo que a gestão pública venha delegando à sociedade civil organizada a função de decidir e fiscalizar algumas ações governamentais, há pouca prática de participação nesse sentido.

A própria lógica de editais precisa ser cuidadosamente acompanhada, principalmente diante das discrepantes possibilidades tanto para concorrer quanto de execução dos projetos, entre universidades privadas e públicas. Ainda que a efetivação das $\mathrm{DCN}^{3}$ seja para todas as graduações, há diferenças institucionais entre universidades que configuram a autonomia e a participação das IES, dos cursos, dos professores, além dos filtros internos de cada universidade diante das relações profissionais e dos poderes instituídos na dinâmica organizacional e destes com os serviços municipais em sua dinâmica interna e interinstitucional.

Mesmo que se institua uma forma mais participativa na execução do programa e de outras ações de formação em saúde com gestão colegiada com a participação de diferentes atores, movimentos, instituições e instâncias governamentais, há muito a se avançar para termos relações mais horizontais e poderes compartilhados entre os membros e instituições envolvidas na formação em saúde seja através de rodas de conversa ou na versão atual de gestão através de Comissões de Integração Ensino-Serviço (CIES).

O comprometimento político, o suporte estrutural e financeiro e a comunicação ampla entre os diversos atores e arranjos institucionais são também dimensões fundamentais para operar mudanças. A participação pode ser direta ou por representação e o voto pode ter o mesmo peso entre os participantes, mas o vínculo e o lugar de onde se fala e o grau de autonomia ou de interdependência entre atores e instituições são diferentes, dinâmicos e, por vezes, desiguais. Ou seja, no exercício da gestão compartilhada, diferentes vozes e interesses estão na mesa para jogar.

Tanto os serviços quanto a universidade apresentam ritmos internos e condições políticas e institucionais específicas, que interferem na consolidação do sistema de saúde, na formação de profissionais e na própria interação entre as duas instituições. Na busca pela

\footnotetext{
${ }^{3}$ Mesmo que os quatorzes cursos de saúde tenham diretrizes curriculares nacionais similares, a adesão ideológica a elas tem especificidades das categorias e associações profissionais, assim como as hierarquizações das profissões de saúde.
} 
efetivação da interação escola-serviço, além do descompasso entre os estabelecimentos já abordado anteriormente (BATISTA, 2013), há também um desencontro ou uma distância entre o funcionamento dos serviços e o ideário do SUS. Isso ocorre não apenas pela defasagem na formação de seus trabalhadores ou concepções em disputas em relação ao SUS que queremos, mas pela própria organização do trabalho e gestão local que enfrenta situações diversas como a baixa fixação de profissionais no serviço, pela insuficiente resolutividade dos casos e escassa efetividade dos fluxos de trabalho e dos encaminhamentos, dentre outras questões organizacionais e estruturais que dificultam a interação interna entre os serviços da rede de saúde e que, consequentemente, afetam a prática em saúde e os processos de formação na relação educação-trabalho.

Morais e outros (2010), em estudo similar a esse já citado, também identifica questões estruturais que limitam o processo de mudança, como a rotatividade de profissionais e de gestores nos serviços que enfraquecem os vínculos e dificulta a continuidade de trabalhos gerando empecilhos para a superação do paradigma 'conteudista' e da pedagogia tradicional, que elege a universidade como produtora de conhecimentos.

A verticalização da relação escola-serviço também é apontada no repasse de informação, no desenvolvimento das atividades, no relato de atitudes passivas e de reprodução por parte dos serviços perante atividades que habituam chegar já organizadas e planejadas por parte da universidade na maioria das vezes, comprometendo a gestão compartilhada dos processos de formação em saúde (MORAIS et al., 2010).

Ainda assim, concordando com Ferreira e outros (2007), que há avanços no Edital PróSaúde em relação às ações de Integração Docente-Assistencial (IDA), em que o recurso era apenas para a universidade. Ao reconhecer interesses comuns e necessidades de recursos para os dois setores, o Pró-Saúde promove uma aproximação entre IES e serviços numa ação interinstitucional integrada, ainda que a efetivação desta parceria tenha um caminho a construir. Com o Pró-Saúde os serviços afetados em sua rotina com a inserção de estágios têm recursos para ajustar seu espaço e funcionamento a essa interação com a escola. Mais que recursos, o programa sinaliza a participação e implicação também dos serviços na formação de profissionais de saúde, postura já presente no PROMED.

Por parte da universidade, segundo Veloso (2008), a mudança de uma estrutura rígida como o currículo enfrenta várias forças: aquelas conservadoras do campo da educação, outras forças corporativistas e do mercado, forças críticas ao processo ou do próprio sentido da mudança, além de grupos que aguardam condições melhores para efetivar tais mudanças ou que esperam que se efetivem a revelia de sua participação. E mais, a mudança enfrenta boicotes, 
seja em forma de não participação das discussões, seja pelo medo de o trabalho aumentar ou por desconhecer o projeto do curso, ou ainda por desejar manter a estrutura de poder e não abandonar o estabelecido e deslocar-se e ir para o desconhecido.

[...] É... eu sinto, muitas vezes, alguns professores [...] boicotando o Pró-Saúde também, né? Porque as pessoas estão muito acomodadas naquilo que eles já conhecem, a mudança mexe muito com as pessoas, né? Então, sair desse estado aí de acomodação é esse desafio, tirar esse professor e esse aluno desse estado. Acho que é o maior desafio (Margarida, professora do curso de fonoaudiologia).

As causas das resistências não são identificadas claramente e não podemos dividir as forças entre conservadoras e transformadores apenas. As relações entre agentes e estruturas sociais exigem análises mais complexas do campo universitário. Alias a universidade não se configuraria como um único campo, mas participaria de pelo menos quatro deles: educacional, profissional, cultural e da pesquisa, o que torna a integração universitária mais complexa conforme Cunha (2005). Assim, mudar um campo como a formação, significa mudar posturas e poderes instituídos, acumular capital simbólico, ou seja, aumentar conhecimento dentro de um campo, obter prestígio e reconhecimento, condição que demanda tempo, embates e variados investimentos (BOURDIEU, 2004; VELOSO, 2008)

Os problemas aos quais que estamos nos referindo, são antigos e acompanharam as diversas iniciativas anteriores pela mudança da formação em saúde (BATISTA, 2013). Se revisitarmos o Programa UNI - Uma Nova Iniciativa na Educação dos Profissionais de Saúde: União com a Comunidade (FEUERWERKER; CHAVES; TANCREDI, 1999), uma experiência universitária de mudança da década de 1990 que teve efeito na conformação de discursos sobre a formação em saúde e sobre a constituição de sujeitos orientados por valores e projetos coletivos, encontraremos pontos comuns com o Pró-Saúde. Os projetos UNI também se basearam na parceria entre serviço e universidade como estratégia potente de mudança a partir de espaços de negociação e certa redistribuição de poder. Porém, tiveram pouca articulação entre si, não ampliando a rede de cooperação conforme seu ideário, o que se assemelha ao Pró-Saúde na universidade estudada. Contudo, o Pró-Saúde não deixa de avançar com a diversificação dos cursos de saúde, a declarada atuação multiprofissional e interdisciplinar e a demanda de interações entre os cursos na mesma universidade, como veremos a seguir. De toda forma, a avaliação do Programa UNI (FEUERWERKER; CHAVES; TANCREDI, 1999), é relevante, pois nos indica a necessidade de adotarmos uma metodologia de gestão de mudança, assim como reconhecermos as posturas de resistência e as tendências de atuação dos docentes em propostas semelhantes. 
Podemos dizer que a submissão de projetos para o Edital Pró-Saúde é voluntária, mas não a adoção das diretrizes. Ao submetermos um projeto ao edital, estamos não apenas buscando auxílio para a reorientação da formação, mas aderindo às diretrizes curriculares e à política de saúde, afirma Veloso (2008). Assim, discutir tanto a atuação docente na execução do programa quanto a lógica de editais e a gestão dos programas são pontos essenciais na busca de reorientar a formação no ensino superior.

\section{O trabalho docente na execução do programa}

Os variados vínculos de trabalho dos docentes na universidade e outros fora dela determinam disponibilidades e intensidades de envolvimento com o projeto como o Pró-Saúde. A situação de trabalho da maior parte dos professores universitários de instituição privada é de contrato hora-aula, ou seja, são poucos professores com horas de trabalho destinadas para além da sala de aula. Dessa forma, recai sobre os professores com horas de dedicação ${ }^{4}$ à universidade grande responsabilidade de participar e coordenar as ações do Pró-Saúde. O próprio RTIRegime de Trabalho Integral, em muitas universidades privadas, é composto por aulas e gestão do curso, sem ou com poucas horas dedicadas especificamente aos projetos e programas, gerando uma sobrecarga aos docentes com 40 horas de dedicação ao assumirem o Pró-Saúde. Ou seja, no caso das universidades privadas, que precisam garantir um mínimo de professores de regime de tempo integral, ainda vigora a lógica do professor 'aulista', e, assim, qualquer novo projeto é acrescido ao trabalho desse docente, sem extensão de horas, já que se encontra atrelado à manutenção do regime na universidade.

\footnotetext{
Então, eu vejo a [universidade]... é... poderia nos favorecer mais, entendeu? Então, é... eu penso nessas reuniões todas, como eu não sou 40 horas, eu não recebo pra vir nessas reuniões. Quando o curso tem horas sobrando, ele: Ah! Vamos dar uma hora pra [fulana] de dedicação, né? Então, esse envolvimento, eu acho que ainda a [universidade] podia abrir mais, porque eu acho que daqui do Pró-Saúde vai sair muita coisa, né? (Margarida, professora do curso de fonoaudiologia)
}

Hoje, eu já até considero um número significativo, uma conquista ao longo desse tempo, que favoreceu um número maior de professores que participam no projeto. Eu vejo que não é assim ... muito por achar o projeto interessante, um projeto bacana, eu acho que isso é até uma coisa que seria comum, a dificuldade maior é dedicação. Porque é uma dedicação que é uma dedicação que vai além do que a

\footnotetext{
${ }^{4}$ A dedicação refere-se a atividade docente de coordenação de curso, de colegiado, de coordenação de extensão e pesquisa, de laboratórios, de clínica-escola, de estágios atribuída com horas pré-estabelecida e salário fixado, previstos dentro do banco de horas de cada curso somadas com as aulas compõem a carga horária e salário do professor, isto é, o RTI. O desenvolvimento de pesquisa, de extensão, ou mesmo a coordenação de pósgraduação ou outras atividades científico-acadêmicas ou programas estão além deste arranjo inicial, muitas vezes. Ou seja, ações e projetos novos são incorporados aos docentes de RTI sem diminuição das atribuições anteriores ou remuneração específica para tal.
} 
própria instituição contrata o professor para isso, então, nosso regime é um regime que não favorece muito, porque o Pró-Saúde, ele exige uma dedicação a mais desse professor, então, eu vejo o que tem por trás aí é uma acomodação. [...] É mais fácil eu manter o aluno na clínica, que tá ali pertinho do que eu ter que mandá-lo para o centro de saúde. No centro de saúde eu vou ter que ir lá, eu vou ter que acompanhar e no centro de saúde ele não é remunerado para isso. O próprio projeto não... não... não dispõe de verba para esse fim, né?! [...] E aí, nós temos dentro desse programa um outro programa, que se chama PET-Saúde, que está prevista uma verba para o professor e a verba para o preceptor. [...] Às vezes, a verba que é destinada para instituição de ensino quanto à prefeitura é uma verba direcionada para bens de consumo, que não está previsto para pagamento desse profissional supervisor, seja na saúde ou na própria instituição. O PET-Saúde já tem está em outra instância, é uma pesquisa onde tem previsão para as pessoas envolvidas, isso é um fator que é um diferencial (Girassol, professora do curso de psicologia).

Perante o edital do Pró-Saúde que não disponibiliza recursos destinados aos professores, alunos ou profissionais do serviço, a execução do programa na instituição é questionada quanto às condições de trabalho. Exige maior dedicação, mas diferentemente do Programa de Educação pelo Trabalho na Saúde (PET-Saúde) não apresenta incentivos financeiros. Assim, houve uma valoração distinta na universidade e no serviço entre dois grupos: os privilegiados do PET e os voluntários do Pró-Saúde.

A fala das entrevistadas aponta como grande desafio do Pró-Saúde o próprio funcionamento da universidade e as condições desfavorecidas de trabalho para uma atuação conjunta, seja pelo fato que as diferenças curriculares, a organização e o funcionamento de cada curso impossibilitam encontros entre os professores, seja pela impossibilidade de estabelecimento de hora comum para reuniões e atuação coletiva devido à diferenciação de vínculos de trabalhos.

As diferenças de disciplinas, de carga horária, de turno, de pré-requisitos, de periodização, são aspectos limitadores para uma formação interdisciplinar, multiprofissional e integrada dentro da própria universidade.

Eu acho que os principais [desafios], do lado da universidade, são os currículos, que acho que ainda estão muito duros, e do lado do serviço, esse entendimento da necessidade da vinda da universidade para dentro do serviço, o entendimento da importância do aluno vivenciar desde o começo o serviço. Aí, eu fico imaginando um currículo ideal [...] um currículo flexível [...] Então, a dificuldade que vejo é o currículo, que é um dos eixos lá do Pró-Saúde. A outra coisa é do serviço, o entendimento disso. O aluno chega aqui, o objetivo tem que casar com o objetivo da instituição também, todos dois têm que ser par (Rosa, professora do curso de fisioterapia).

O desafio também é, é, é isso, né? É um horário que seria mais flexível, né? Uma, uma ação conjunta com os coordenadores de estágio, é... Se fosse um, um... eи acho que seria meu desejo maior né? que todos os estágios funcionassem da mesma maneira, né? (Margarida, professora do curso de fonoaudiologia).

Eu acho que as condições, eu acho que tem que ter, não é que tenha que ter hora, porque o programa de reorientação, ele tem que ser incorporado por todas as disciplinas. Ele não é mais um serviço, é você dentro da sua disciplina, planejar sua disciplina, implementar e avaliar sua disciplina, tendo em mente que você quer formar um aluno com a competência $X$, capaz de dar resposta às questões de saúde da população. Mas existem situações em que o planejamento e o desenvolvimento dessas ações, elas 
extrapolam o período de extraclasse do professor, demandam muito trabalho e compromisso pessoal de cada profissional envolvido nas comissões, né? Então, eu acho que uma das questões seria realmente condição de trabalho, ter horas pra ele [...] daquele sujeito que está sendo o pensante, que está sendo o agregador, que está sendo o planejador, o executor de todas as ações que são para fora de sala de aula. [...] (Jasmim, professora do curso de enfermagem).

Ainda que as deficiências na organização e condições de trabalho persistam nas colocações das entrevistadas com destaque para a precariedade da contratação de professores 'aulistas' e a sobrecarga dos professores de dedicação, os cursos se conheceram e desenvolveram ações compartilhadas que, por sua vez, geram reflexões em torno da interdisciplinaridade e da atuação multiprofissional e em equipe.

\begin{abstract}
Eu acho que, assim, ele [Pró-saúde] foi responsável, sim, por vários... vários processos dentro da universidade e principalmente, assim, ele possibilitou conversar sobre a formação num eixo que extrapola o eixo institucional. Então, assim, a pró-reitoria de graduação conversava da formação do seu curso só com eles. Isso não tinha nenhum tipo de parâmetro ou de conversa entre os outros cursos. E eu acho que isso é uma questão que a gente tem que tá vendo como um avanço, né? É... acho que o reconhecimento que a rede também teve ao que a [universidade] conseguiu construir, apesar de todas essas dificuldades que foram colocadas. [...] Então, eu acho que é um programa que movimentou, que trouxe conceitos novos pra prática do docente e que tem o valor, independente de conseguir ser fechado como tava lá no projeto, mas eu acho que tem seu valor pelo que ele já gerou de mudanças (Jasmim, professora do curso de enfermagem).
\end{abstract}

Então né?, o trabalho mais integrado tem acontecido nos espaços mais escolares, na escola, né? Embora a gente saiba que tem outras possibilidades, mas isso tem sido difícil e essa dificuldade não é função do professor não querer, é em função da própria dinâmica do funcionamento. Então, os cursos têm funcionamentos diferentes, a fisio, a fono, o supervisor fica lá no campo de estágio. Então, todos os alunos estão fazendo a mesma coisa, no mesmo dia, no mesmo horário, nós não. Nós, enquanto supervisores da [universidade], então, nós temos alunos em várias instituições dentro da mesma proposta de estágio, fazendo coisas diferentes. Então, isso não possibilita que no dia da supervisão eu possa estar no Centro de Saúde. Então, esse funcionamento é diferente. Então, um aluno vai escolher os dias que vai estar lá. [...] Então, assim, não é uma falta de querer ou uma falta de vontade, tem todo um questionamento, assim, da dinâmica de funcionamento aí por trás, que dificulta muito isso, né? essa atividade. [...] Então, esse é o primeiro passo, estar no mesmo espaço físico, para depois estar no mesmo dia e no mesmo horário [...] (Girassol, professora do curso de psicologia).

A relação entre intercursos, a aproximação da rede de serviços e o desafio da atuação interdisciplinar, também são apontadas por Almeida e outros (2012) como efeito do Pró-Saúde. Carvalho e Ceccim (2006) assinalam que é preciso haver transversalidade na formação com práticas intercursos e permeabilidades multiprofissionais que devem ser valorizadas e procuradas na universidade. De fato, para atuar multiprofissionalmente e posicionar interdisciplinarmente, é preciso minimamente conhecer os demais cursos, as disciplinas e as atuações de cada profissão. E nesse sentido, o discurso da necessidade de todos profissionais trabalharem em equipe é forte nas entrevistas, bem como a importância do programa para a interação entre os cursos na universidade, ainda que esse discurso apareça ausente de conflitos e disputas. 
É importante lembrar que, assim como os serviços de saúde, a universidade não está imune à hierarquização disciplinar e a disputas profissionais. Na regulamentação do exercício profissional, tanto na dimensão do trabalho quanto da formação, as competências específicas compreendem saberes-fazeres-poderes que, no jogo de interesses, contracenam com o mercado, deixando os confrontos extrapolarem os perímetros epistemológicos (SPINK, 2009).

Mesmo que as ações interdisciplinares estejam dentro do próprio curso e não entre os cursos, há uma preocupação com essa postura na formação em saúde, ainda que esteja pouco refletida nos currículos. As modificações nas disciplinas são internas a cada curso, com mais mudança de temáticas ou periodização e ainda com ênfase na transmissão de conhecimento. $\mathrm{O}$ currículo permanece focado na formação técnica específica avançando lentamente para a integralidade perante fronteiras disciplinares e profissionais pouco permeáveis.

O viés interdisciplinar e do trabalho multiprofissional proposto pelo SUS e reafirmado pela saúde coletiva parece ter impactado pouco a graduação. A universidade pouco borra os campos disciplinares ou provoca porosidade às identidades profissionais, já que a lógica mercadológica não deixa de operar. Essa lógica e malha disciplinar atravessa o trabalho de profissionais tanto nas universidades quanto nos serviços, tornando complexo o cumprimento de políticas e de seus programas.

\section{Considerações}

A análise de programas de indução como o Pro-Saúde tendem a evidenciar conflitos e resistências na disputa do campo da formação em saúde, que tencionam as relações entre universidade, mercado e identidade profissional em suas dimensões epistemológica, ideológica e também econômica, o que torna as universidades privadas mais vulneráveis já que estas proporcionam um menor grau de autonomia institucional na correlação de forças, sobretudo nas modalidades de contrato de trabalho dos docentes e na participação ampla e democrática.

O caso estudado retrata algumas limitações da lógica governamental de indução de mudanças na educação superior por editais, principalmente pelas condições de atuação e de gestão do programa em um contexto universitário privado onde se formam a maioria de profissionais de saúde do país.

De fato, era improvável que a disputa entre os saberes, cursos e profissões dentro da universidade e desta com o serviço, parceiro no projeto, aparecessem explicitamente nas entrevistas desta pesquisa. Precisaremos de mais estudos com outros desenhos metodológicos para abordarmos as relações e grupos de interesse presentes nas instituições que incidem no 
acesso e circulação de informações, nos processos decisórios, nos critérios para participar dos editais, na definição da distribuição de recursos dentre outros, para propiciar uma gestão da mudança que considere o ciclo de vida dos programas, seus princípios, os vínculos institucionais e suas descontinuidades.

A mudança requer um rompimento que nos lança ao risco e à invenção. Todavia, além de tempo, as mudanças exigem condições ou mesmo uma dependência de trajeto, sendo provocadas por redesenhos institucionais e incentivos públicos que possam vir a instaurar ou somar-se a mudanças sociais mais profundas, não somente nos currículos.

\section{Referências}

ALMEIDA, Magda Moura de; MORAIS, Rui Porto; GUIMARAES, Danilo Frota; MACHADO, Maria de Fátima Antero Sousa; DINIZ, Rita de Cássia Moura; NUTO, Sharmênia de Araújo Soares. Da teoria à prática da interdisciplinaridade: a experiência do Pró-Saúde Unifor e seus nove cursos de graduação. Revista Brasileira de Educação Médica, Brasília, v. 36, n.1, p. 119-126, 2012. Disponível em: <http://www.scielo. br/scielo.php?script=sci_arttext\&pid=S0100-55022012000200016\&lng=pt\&nrm=iso>. Acesso em: 11 set. 2016.

BARBOSA, Maria Ligia de Oliveira; SANTOS, Clarissa Tagliari. A permeabilidade social das carreiras do ensino superior. Cad. CRH, Salvador, v. 24, n. 63, p. 535-554, dez. 2011. Disponível em: <http://www.scielo.br/scielo.php?script=sci_arttext\&pid=S0103-497920 11000300006\&lng=en\&nrm=iso>. Acesso em: 11 set. 2016.

BATISTA, Cássia Beatriz. Movimentos de reorientação da formação em saúde e as iniciativas ministeriais para as universidades. Revista Barbarói, Santa Cruz do Sul, n. 38, p. 97-125, jan./jun. 2013. Disponível em: <https://online.unisc.br/seer/index.php/barbaroi /article/view/2567/ 2 734>. Acesso em: 11 set. 2016.

BATISTA, Cássia Beatriz. Pró-saúde e o contexto universitário: achados de uma pesquisaexperiência. In: BOCK Ana Mercês Bahia, BARROSO, Lúcia Maria Ozório; DIEHL Rafael; MORTADA, Samir Pérez (Orgs.). Práticas e saberes psi: os novos desafios à formação do psicólogo. Florianópolis: ABRAPSO: Edições do Bosque/CFH/UFSC, 2015. Disponível em <http://www.abrapso.org.br/download/download?ID_DOWNLOAD=472>. Acesso em: 20 set. 2016.

BONFIM, Washington Luís de Sousa; SILVA, Irismar Nascimento da. Instituições políticas, cidadania e participação: a mudança social ainda é possível? Rev. Sociol. Polit., Curitiba, n. 21, p. 109-123, nov. 2003. Disponível em: <http://www.scielo.br/scielo.php?script=sci_ arttext\&pid=S0104-44782003000200008\&lng=en\&nrm=iso>. Acesso em: 11 set. 2016.

BOURDIEU, Pierre. Os usos sociais da ciência: por uma sociologia clínica do campo científico. São Paulo: UNESP, 2004.

BRASIL. Lei n $^{\circ} 8.080$, de 19 de setembro de 1990. Dispõe sobre as condições para a promoção, proteção e recuperação da saúde, a organização e o funcionamento dos serviços correspondentes e dá outras providências. Diário Oficial [da] República Federativa do Brasil, Brasília, DF, 20 set. 1990. Seção 1, p. 15. 
BRASIL. Portaria Interministerial MS/MEC n 3.019, de 27 de novembro de 2007. Dispõe sobre o Programa Nacional de Reorientação da Formação Profissional em Saúde - Pró- Saúde - para os cursos de graduação da área da saúde. Diário Oficial [da] República Federativa do Brasil. Brasília, DF, 27 nov. 2007.

CARVALHO, Yara Maria de; CECCIM, Ricardo Burg. Formação e educação em saúde: aprendizados com a saúde coletiva. In: CAMPOS, G.W. (Org.). Tratado de saúde coletiva, São Paulo; Rio de Janeiro: Hucitec-Fiocruz, 2006. p.137-170.

CUNHA, Luiz Antônio. Autonomia universitária: teoria e prática. Avaliação, Campinas; Sorocaba, v. 10, n. 1, 2005. Disponível em:

$<$ http://periodicos.uniso.br/ojs/index.php?journal=avaliacao\&page=article \&op=view \&path\% B\% 5D=1295\&path\%5B\%5D=1286>. Acesso em: 11 set. 2016.

FERREIRA, José Roberto; CURY, Geraldo Cunha; CAMPOS, Francisco Eduardo; HADDAD, Ana Estela; GUSSO, Gustavo Diniz Ferreira. A construção de parcerias como estratégia para o sucesso do Pró- Saúde. Cadernos ABEM, Rio de Janeiro, n. 3, p. 53-61, 2007. Disponível em: <http://abem-educmed.org.br//wp-content/uploads/2016/06/Cadernos ABEM_Vol03.pdf>. Acesso em: 11 set. 2016.

FEUERWERKER, Laura Camargo Macruz; CHAVES, Mário; TANCREDI, Francisco Bernardini. Revisitando o ideário e reconstruindo a proposta. In: ALMEIDA, Márcio; FEUERWERKER, Laura; LLANOS, Manuel. (Org.). Educação dos profissionais na América Latina: teoria e prática de um movimento de mudança. São Paulo: Hucitec, 1999. p. 165- 183.

MINAYO, Maria Cecília de Souza. O desafio do conhecimento: pesquisa qualitativa em saúde. 7. ed. São Paulo: Hucitec, 2000.

MORAIS, Fátima Raquel Rosado; LEITE, Ilana Deyse Rocha; OLIVEIRA, Lucineire Lopes de; VERÁS, Renata Meira. A reorientação do ensino e da prática em enfermagem:

implantação do Pró-Saúde em Mossoró, Brasil. Rev. Gaúcha Enferm, Porto Alegre, v. 31, n. 3, p. 442-449, set. 2010. Disponível em:

$<$ http://www.scielo.br/scielo.php?script=sci_arttext\&pid=S1983-

$14472010000300006 \& \operatorname{lng}=$ en\&nrm=iso>. Acesso em: 11 set. 2016.

SANTOS, Boaventura de Sousa. Da ideia de universidade à universidade de ideias. In:

SANTOS, Boaventura de Sousa. Pela mão de Alice: o social e o político na pósmodernidade. 13. ed. São Paulo: Cortez, 2010. p. 187-233.

SPINK, Mary Jane. Saúde: um campo transdisciplinar? In: SPINK, Mary Jane. Psicologia social e saúde: práticas, saberes e sentidos. 5.ed. Petrópolis: Vozes, 2009. p. 51-60.

STANGA, Adriani Cristiani; REZER, Ricardo. Concepções de saúde, trabalho docente e o Pró-Saúde: nos caminhos da hermenêutica. Physis, Rio de Janeiro, v. 25, n. 2, p. 593-

614, jun. 2015. Disponível em:

<http://www.scielo.br/scielo.php?script=sci_arttext\&pid=S0103-

73312015000200593\&lng=en\&nrm=iso>. Acesso em: 11 set. 2016.

VELOSO, Tereza Christina Mertens Aguiar. Programa Nacional de Incentivo a Mudanças

Curriculares no Curso de Medicina: experiências da UFG. 2008. Tese (Doutorado) Programa de Pós-Graduação em Educação, Universidade Federal de Goiás, Goiânia, 2008. 
Cássia Beatriz Batista Universidade Federal de São João Del Rei | Departamento de Psicologia São João Del Rei | MG | Brasil. Contato: cassiabeatrizb@gmail.com ORCID (iD) https://orcid.org/0000-0002-9393-0340

Cornelis Johannes van Stralen Universidade Federal de Minas Gerais | Faculdade de Filosofia e Ciências Humanas | Departamento de Psicologia Belo Horizonte | MG | Brasil. Contato: stralen@ medicina.ufmg.br ORCID (ID) https://orcid.org/0000-0003-0921-098X

Artigo recebido em 21 de setembro de 2016 e aprovado em 4 de julho de 2017. 